\title{
Protective effect of Achyranthes bidentata polypeptides on NMDA-mediated injury is developmentally regulated via modulating NR2A and NR2B differentially
}

\author{
Wenqing $\mathrm{Hu}^{1,2}$, Jianghong $\mathrm{He}^{1}$, Yu Wang ${ }^{1}$, Lingchi $\mathrm{Xu}^{1}$, Ying $\mathrm{Zhao}^{1}$, Xinping $\mathrm{Hu}^{3}$, Hongmei Shen ${ }^{1,4} \wedge$ \\ ${ }^{1}$ Key Laboratory of Neuroregeneration of Jiangsu and Ministry of Education, Co-innovation Center of Neuroregeneration, Nantong University, \\ Nantong, China; ${ }^{2}$ Department of Bioengineering, Jacobs School of Engineering, UC San Diego, La Jolla, CA, USA; ${ }^{3}$ Department of Information \\ Technology, Library of Nantong University, Nantong University, Nantong, China; ${ }^{4}$ Affiliated Mental Health Center of Nantong University, Brain \\ Hospital of Nantong City, Nantong, China \\ Contributions: (I) Conception and design: W Hu, H Shen; (II) Administrative support: X Hu, H Shen; (III) Provision of study materials or patients: W \\ Hu, J He, W Yu, L Xu, Y Zhao; (IV) Collection and assembly of data: X Hu, J He, W Hu; (V) Data analysis and interpretation: W Hu, H Shen; (VI) \\ Manuscript writing: All authors; (VII) Final approval of manuscript: All authors. \\ Correspondence to: Hongmei Shen. Key Laboratory of Neuroregeneration of Jiangsu and Ministry of Education, Co-innovation Center of \\ Neuroregeneration, Nantong University, Nantong 226001, China. Email: shmhu@ntu.edu.cn; Xinping Hu. Department of Information Technology, \\ Library of Nantong University, Nantong University, Nantong 226019, China. Email: xphu@ntu.edu.cn.
}

\begin{abstract}
Background: Achyranthes bidentata polypeptides (ABPPs) are a potent intervention for excitotoxicityrelated disorders such as Parkinson's disease and ischemic stroke. Previous work suggests that overstimulation of N-methyl-D-aspartate (NMDA) receptors plays a critical role in excitotoxicity, and expression of NR2 subunit variations is developmentally regulated. Our current study focused on neuroprotection of ABPPs on cultured neurons by modulation of NR2A and NR2B differentially.

Methods: Primary cultured neurons were treated with NVP-AAM077, Ro-256981, ABPPs, and then the neurons were exposed to NMDA to induce excitotoxicity. Cellular viability was detected promptly and 24hour after exposure to NMDA by MTT assay. Patch-clamp recording was applied to evaluate the effect of ABPPs on NMDA-evoked current and the differential modulation of ABPPs on NR2A and NR2B subunits in conjunction with NVP-AAM077 and Ro-256981.

Results: ABPPs $(10 \mu \mathrm{g} / \mathrm{mL})$ blocked neuronal injury by NMDA in mature cultures, and the peptides conferred neuroprotection in immature cultures unless co-applied with NVP-AAM077. Furthermore, ABPPs enhanced NMDA current in mature cultures, while decreasing NMDA current in immature cultures. On the other hand, we showed that ABPPs increased NMDA current when Ro-256981 was present and decreased NMDA current when NVP-AAM007 was present.

Conclusions: Neuroprotection of ABPPs on NMDA-mediated injury differentially in immature and mature cultures involves enhancement of NR2A subunits and prevention of NR2B subunits, indicating that dosage of ABPP should be considered in treatment with patients at different developmental stages.
\end{abstract}

Keywords: Achyranthes bidentata polypeptides (ABPPs); development; neuroprotection; N-methyl-D-aspartate (NMDA) receptor

Submitted Jan 10, 2020. Accepted for publication Nov 15, 2020.

doi: $10.21037 /$ atm-20-581

View this article at: http://dx.doi.org/10.21037/atm-20-581

^ ORCID: 0000-0003-0048-4554. 


\section{Introduction}

Glutamate is one of the most prevalent excitatory neurotransmitters in the mammalian central nervous system (CNS), where it is essential for the rapid excitatory signals. During neurotransmission, glutamate is released to synaptic cleft, and some of them is spilled over to extra-synapses (1). Residual glutamate in the extrasynapses is cleared by glutamate uptake transporters, which are expressed, principally, in astrocytes to keep extracellular glutamate at low concentration (2). In the brain, extracellular glutamate level ranges between 0.18 and $2.12 \mu \mathrm{M}$ to avoid neurotoxicity (3-6). The pathological accumulation of extracellular glutamate, referred to as excitotoxicity, contributes to a broad range of neurological and neuropsychiatric diseases, including ischemic stroke, Parkinson's diseases, epilepsy, Huntington's disease, mood disorders and schizophrenia (2).

N-methyl-D-aspartate receptors (NMDARs), a calcium permeable ionotropic glutamate receptor family, play a fundamental role in the mechanisms of excitotoxicity (7). Typically, NMDAR comprises two obligatory NR1 and two regulatory NR2, which have been identified four variations (NR2A-2D) $(8,9)$. In the hippocampus, NMDARs mainly contain NR1 subunits in combination with NR2A or NR2B subunits, and expression of NR2 subunit variations switches from NR2B to NR2A during development (10-13).

A.bidentata poplypeptides (ABPPs) were obtained by means of classical salting-out sedimentation with ammonium sulfate from the extract of A.bidentata Blume root decoction (14). Calcium imaging data showed that ABPPs block NR2B-containing NMDARs, and enhance function of NR2A-containing NMDARs in cultured hippocampal neurons (14). However, during development, the change in the expression of NR2 subunit variations is observed in primary cultured neurons. Immature cultures (7 days in vitro) contain mainly NR2B subunits, while mature cultures (14 days in vitro) express mostly NR2A subunits $(8,15)$. Therefore, in the current study, we assessed the neuroprotective effect of ABPPs on NMDAmediated excitotoxicity in immature and mature cultured hippocampal neurons, and clarified the differential modulation of ABPPs on NR2A- and NR2B-containing NMDAR by electrophysiological recording technique. We present the following article in accordance with the MDAR checklist (available at http://dx.doi.org/10.21037/atm-20581).

\section{Methods}

\section{Preparation of $A B P P s$}

A. bidentata Blume root was powdered and soaked in ultrapure water at $80^{\circ} \mathrm{C}$. ABPPs were subsequently prepared as described by Shen et al. (14). Briefly, the decoction was saturated with ammonium sulfate, and the precipitate was collected by centrifugation. After desalination in 1,000 MW cutoff tubing with ultrapure water, the dialysate was lyophilized into a powder of ABPPs, which are soluble in water. The ABPPs were characterized by high performance liquid chromatography (14).

\section{Primary hippocampal neuron culture}

The whole study protocol was approved by the Ethics Committee of Nantong University (No. 20080118-001) and all the procedures were followed by the Chinese Guidelines for the Care and Use of Laboratory Animals.

All experiments were implemented on primary cultures of rat hippocampal neurons. Tissues were isolated from embryonic day 18 Sprague-Dawley (SD) rats, and prepared as previously (16). Briefly, the whole fetal brains were quickly dissected out, and the hippocampi were harvested and digested with $0.25 \%$ tyrosine (Gibco, New York, NY, USA) at $37{ }^{\circ} \mathrm{C}$ for $5 \mathrm{~min}$. Neurons were cultured in Dulbecco's modified Eagle's medium (DMEM, Gibco), supplemented with $10 \%$ fetal bovine serum (FBS, Gibco), and were plated at a density of $[6-8] \times 10^{4}$ cells $/ \mathrm{cm}^{2}$ onto poly-D-lysinecoated 96-well plates or $8 \mathrm{~mm}$ glass coverslips in dishes. After 24 hours, the medium was replaced with Neurobasal medium (Gibco) containing 2\% B27 supplement (Gibco) and glutamine (0.5 mM, Gibco). After that, half of the medium was replaced with fresh medium every 3 days.

\section{NMDA-induced neuronal injury model and cell treatment}

Neurotoxicity was triggered by exposing primary cultured hippocampal cells to high-concentration NMDA (Sigma, St Louis, MO, USA). Because of the blockage by $\mathrm{Mg}^{2+}$ of NMDA receptors, hippocampal cultures, at 7 or 14 days in vitro, were washed with $\mathrm{Mg}^{2+}$-free extracellular solution (ECS) $\left(\mathrm{CaCl}_{2} 2 \mathrm{mM}, \mathrm{NaCl} 140 \mathrm{mM}\right.$, KCl 3 mM, HEPES $10 \mathrm{mM}$, glucose $10 \mathrm{mM}$, pH 7.2-7.3, Osmotic pressure $290 \pm 5 \mathrm{mOsmol} / \mathrm{L})$. After washing, NMDA in $\mathrm{Mg}^{2+}$-free ECS was added to the wells to evoke excitotoxicity. After 
NMDA stimulation, cultures were washed three times with $\mathrm{Mg}^{2+}$-free ECS and returned to the original medium. ABPP, Ro-256981, NVP-AAM077, or (+)-5-methyl-10, 11-dihydro5H-dibenzo (a, d) cyclohepten-5, 10-imine maleate (MK-801, Sigma) was added 12-hour prior to NMDA stimulation until the excitotoxic insult was complete.

\section{Assessment of neuronal cell viability}

Cellular viability measurements were performed promptly and after 24 hours of exposure to NMDA using 3-(4,5-dimethylthiazol-2-yl)-2,5-diphenyltetrazolium bromide (MTT, Sigma) assay. The detailed methods were described previously by Shen et al. (14). Data were expressed as the percentage value, which was normalized to the control cultures (Elx 800, Bio-TEK Instruments Inc., VT).

\section{Electrophysiological recording}

Receptors for NMDA that are ligand-gated ion channels play a critical role in NMDA-induced neurotoxicity (17). The activation of NMDA receptors is identified by the influx of $\mathrm{Na}^{+}, \mathrm{Cl}^{-}, \mathrm{Ca}^{2+}$ ions, which are examined by whole-cell patch clamp recording in cultured hippocampal neurons (18). The NMDA-elicited currents were measured in $\mathrm{Mg}^{2+}-$ free solution containing $\mathrm{Ca}^{2+}(2 \mathrm{mM})$, with 2-minute bath perfusion after NMDA current was recorded. All detailed procedures were described previously by Shen et al. (19). The change of amplitude NMDA currents was expressed as the percentage value, which was normalized to the basal level recording in the same hippocampal neuron.

\section{Statistical analysis}

All data were expressed as means \pm SD. Significance was analyzed by one way analysis of variance (ANOVA) with sigmaplot 13.0 software packages (Systat, San Jose, CA, USA), and differences between two groups were assessed by Student-Newman-Keuls post hoc test. The value of $\mathrm{P}<0.05$ was considered statistically significant. All data and statistical analysis comply with the recommendations on experimental design and analysis in pharmacology (20).

\section{Results}

\section{Neuroprotective effects of ABPPs on immature cultures}

Primary cultured hippocampal neurons (DIV7) were exposed to an increasing concentration of NMDA (10-1,000 $\mu M)$ for 1hour. NMDA induced a concentration-dependent reduction in cell viability of hippocampal neurons, as detected immediately after NMDA stimulation by MTT assay (Figure 1A). Exposure to $300 \mu \mathrm{M}$ NMDA for 1 hour was used to induce excitotoxic neuronal injury in the ensuing test.

In hippocampus, majority of NMDARs are either NR2Bcontaining or/and NR2A-containing receptors. Treatment with Ro-256981, a specific NR2B subunit antagonist, or NVP-AAM077, a specific NR2A subunit antagonist, prevented NMDA-induced cell injury in a concentrationdependent manner (Figure 1B,C), suggesting that overactivation of NR2B-containing or NR2A-containing NMDA receptors contributes to NMDA-induced neuronal injury in immature cultures. NMDA-induced excitotoxicity was also blocked by $10 \mu \mathrm{M}$ MK-801, the gold standard of neuroprotective NMDA antagonists (Figure 1C). However, treatment with ABPP $(0.1-10 \mu \mathrm{M})$ did not prevent NMDAinduced cellular viability decrease, which was detected immediately after NMDA stimulation (Figure 1D).

Over stimulation of NMDA receptors induced apoptotic cell death, characterized by Hoechst/PI doubled staining and DNA ladder detection at 24-hour after exposure to NMDA, in rat cultured hippocampal neurons (14). NMDAstimulation resulted in the decrease of cellular viability, which was assessed by MTT at 24-hour after exposure to NMDA, in a concentration dependent way (Figure 1E). Thus, NMDA-mediated apoptotic cell viability decrease was detected at 24 hours after exposure to $300 \mu \mathrm{M}$ NMDA for 1 hour.

To verify that NMDA-induced apoptotic cell injury required NR2B-containing and NR2A-containing receptors, immature cultures were treated with Ro-256981 or NVPAAM077 for 1 hour before NMDA stimulation. Data showed that NMDA-mediated excitotoxicity was blocked by Ro-256981, NVP-AAM077 or MK-801 (Figure 1F,G), proving that overactivation of NR2B-containing or NR2A-containing NMDA receptors contributes to NMDA-induced apoptotic cell injury in primary cultured hippocampal neurons (DIV7). Interestingly, treatment of cultures with ABPP $(0.1 \mu \mathrm{g} / \mathrm{mL})$ blocked NMDA-induced delayed damage, while ABPP $(10 \mu \mathrm{g} / \mathrm{mL})$ treatment could not (Figure $1 H)$. However, treatment of neurons with ABPP $(10 \mu \mathrm{g} / \mathrm{mL})$ prevented NMDA-induced apoptotic injury in combination with NVP-AAM077 $(5 \mu \mathrm{M})$. These data might imply that ABPP $(10 \mu \mathrm{g} / \mathrm{mL})$ could not confer the neuroprotection because of its overactivation on NR2Acontaining NMDA receptors. 

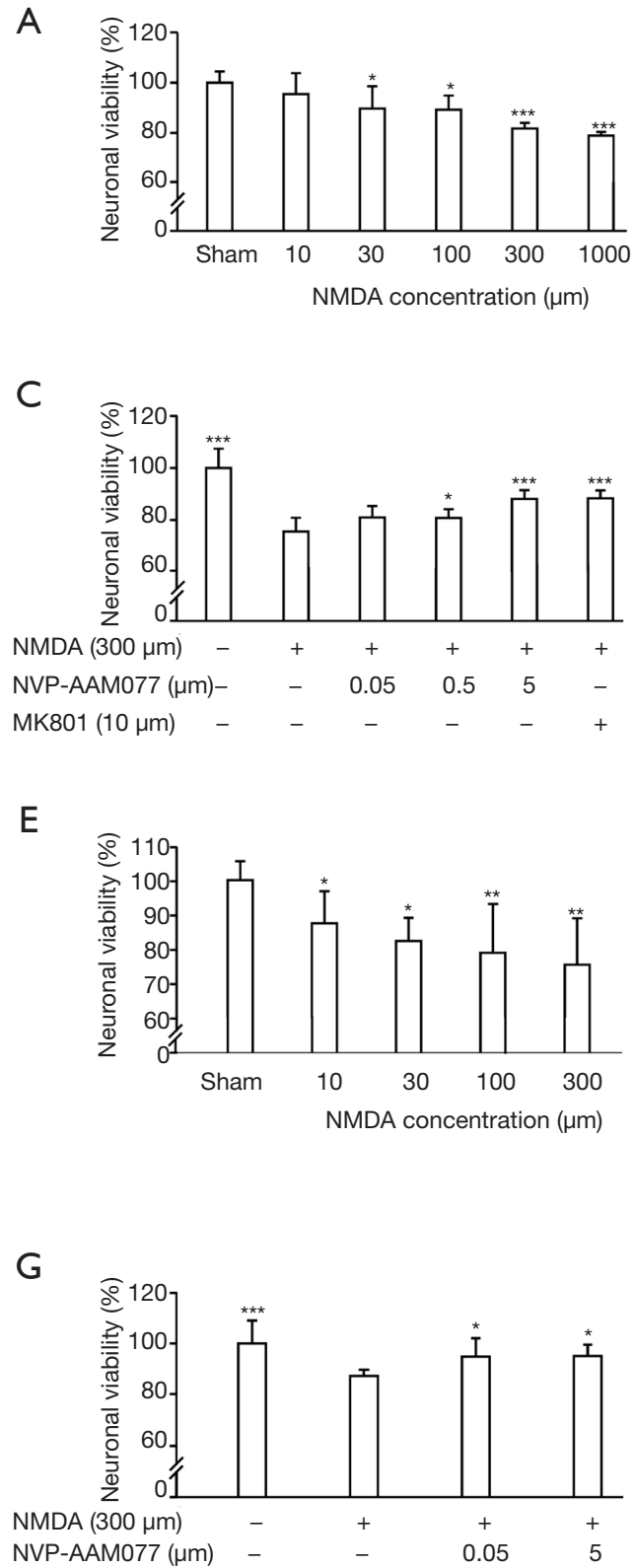
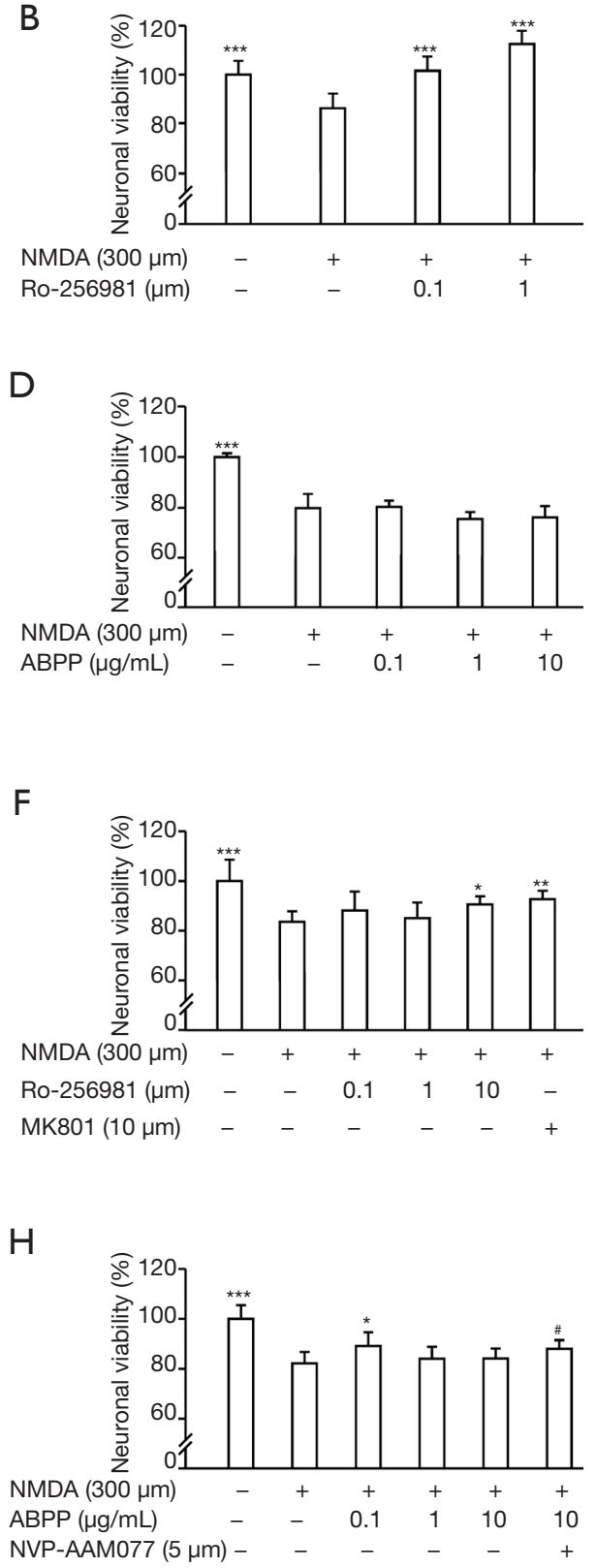

Figure 1 Level of NMDA-induced excitotoxicity was alleviated by ABPP $(0.1 \mu \mathrm{g} / \mathrm{mL})$ in cultured hippocampal neurons at DIV 7 . Cell viability was measured after NMDA stimulation (A-D). NMDA induced a concentration-dependent decrease in cell viability of cultured hippocampal neurons (A). Application of Ro-256981 and NVP-AAM077 along with NMDA prevented NMDA-mediated excitotoxicity in a concentration-dependent manner (B,C), while application of ABPP $(0.1,1,10 \mu \mathrm{g} / \mathrm{mL})$ with NMDA could not block NMDA-mediated excitotoxicity (D). Cell viability was detected at 24 hours after NMDA stimulation (E-H). NMDA induced a concentration-dependent decrease in cell viability of cultured hippocampal neurons (E). Application of Ro-256981 and NVP-AAM077 with NMDA blocked NMDAmediated excitotoxicity in a concentration-dependent manner (F,G). Application of ABPP $(0.1 \mu \mathrm{g} / \mathrm{mL}) \mathrm{prevented} \mathrm{NMDA-mediated}$ excitotoxicity, while other concentrations of $\operatorname{ABPP}(1,10 \mu \mathrm{g} / \mathrm{mL})$ could not $(\mathrm{H})$. However, concurrent treatment of $\mathrm{ABPP}(10 \mu \mathrm{g} / \mathrm{mL})$ with NVP-AAM $(5 \mu \mathrm{M})$ blocked NMDA-induced excitotoxicity $(\mathrm{H})$. NMDA-mediated excitotoxicity was also blocked by $10 \mu M \quad M K-801$ $(\mathrm{C}, \mathrm{F}) .{ }^{*} \mathrm{P}<0.05,{ }^{* *} \mathrm{P}<0.01,{ }^{* * *} \mathrm{P}<0.001$ vs. control group. The NMDA stimulation neurons were referred as control group (A-H). ${ }^{*} \mathrm{P}<0.05$ vs. concurrent treatment with ABPP $(10 \mu \mathrm{g} / \mathrm{mL})$ and NMDA group (H). NMDA, N-methyl-D-aspartate; ABPP, achyranthes bidentata polypeptide. 
Thus, NR2A-containing and NR2B-containing NMDA receptors have identical function on NMDA-mediated cellular injury in primary cultured hippocampal neurons (DIV7). In addition, ABPP, only in low concentration, confers neuroprotective effect on NMDA-induced apoptotic damage in immature cultures.

\section{Neuroprotective effects of ABPPs on mature cultures}

Cultured hippocampal neurons (DIV14) were exposed to an increasing concentration of NMDA $(10-1,000 \mu \mathrm{M})$ for 1 hour. Data showed that NMDA evoked the decrease of cell viability, which was measured immediately after NMDA stimulation, in a concentration dependent manner (Figure 2A). NMDA-mediated neurotoxicity was blocked by Ro-256981, NVP-AAM077, or MK-801 (Figure 2B,C), but ABPP $(0.1-10 \mu M)$ did not prevent the transient decrease of neuronal cell viability by NMDA stimulation (Figure 2D).

Neuronal cell viability was assessed by MTT at 24-hour after exposure to an increasing concentration of NMDA $(10-1,000 \mu M)$ for 1 hour. The results showed that the cellular viability of hippocampal neurons (DIV14) decreased in a concentration dependent manner (Figure 2E), and the NMDA-mediated excitotoxicity was prevented by Ro-256981 and MK-801 significantly (Figure 2F,G). However, NVPAAM077, a specific NR2A subunit antagonist, aggravated the NMDA-mediated apoptotic excitotoxicity (Figure 2G). Additionally, treatment of neurons with ABPP $(0.1-10 \mu \mathrm{g} / \mathrm{mL})$ prevented NMDA-induced apoptotic injury in primary cultured hippocampal neurons (DIV 14) (Figure 2H).

Taken together, NR2A-containing and NR2B-containing NMDA receptors play an identical role on NMDAmediated transient injury in primary cultured hippocampal neurons (DIV14). However, NR2A-containing and NR2Bcontaining NMDA receptors have different function on NMDA-induced apoptotic injury, which detected at 24-hour after NMDA stimulation, in mature cultures. Thus, both low and high concentrations of ABPP confer neuroprotective effect on NMDA-induced apoptotic injury in primary cultured hippocampal neurons (DIV 14).

\section{Regulatory effects of ABPPs on NMDA-evoked current (Figure 3)}

To investigate the differential effects of $\mathrm{ABPPs}$ on immature and mature hippocampal neurons, we examined the NMDA-evoked current by whole-cell patch clamp recording. ABPP $(10 \mu \mathrm{g} / \mathrm{mL})$ did not evoke a significant current (Figure $3 A$ ). However, NMDA $(300 \mu \mathrm{M})$ induced a significant current, which was divided into two sections: the peak current (Ip) and the sustained state current (Iss) (Figure 3B). The sustained state current was inhibited by ABPPs in a concentration dependent manner (Figure 3C,E), while coefficient of desensitization of NMDA currents was promoted by ABPPs in primary cultured hippocampal neurons (DIV 7) (Figure 3D,E). In primary cultured hippocampal neurons (DIV 14), ABPPs elevated the amplitude of the peak and sustained state current (Figure $3 F, G$ ), while coefficient of desensitization of NMDA currents dropped off (Figure 3G,H). Since NR2 subunit variations switches from NR2B to NR2A during development in cultured hippocampal neurons (21-24), the results suggested that ABPPs might modulate NR2A-containing and NR2Bcontaining NMDA receptors in a differential way.

\section{Different regulatory effects of ABPPs on NR2A- and NR2B-containing NMDA receptors (Figure 4)}

In primary cultured hippocampal neuron, NMDA $(300 \mu \mathrm{M})$ evoked a significant current, which was totally blocked by Ro$256981(0.5 \mu \mathrm{M})$ and NVP-AAM077 $(0.7 \mu \mathrm{M})$ (Figure 4A). The addition of Ro-256981 (0.5 $\mu \mathrm{M})$ alone lowered the amplitude of the peak and the sustained state of NMDA $(300 \mu \mathrm{M})$-evoked current, and the simultaneous addition of Ro-256981 $(0.5 \mu \mathrm{M})$ and ABPPs $(1 \mu \mathrm{g} / \mathrm{mL})$ inversely raised the amplitude of the peak and the sustained state of NMDA $(300 \mu \mathrm{M}$ )-evoked current (Figure 4B,D). On the contrary, the addition of NVP-AAM077 $(0.7 \mu M)$ alone lowered the amplitude of the peak and the sustained state of NMDA $(300 \mu \mathrm{M})$-evoked current, and the simultaneous addition of NVP-AAM077 $(0.7 \mu \mathrm{M})$ and ABPPs $(1 \mu \mathrm{g} / \mathrm{mL})$ further lowered the amplitude of the peak and the sustained state of NMDA $(300 \mu \mathrm{M})$-evoked current (Figure $4 E, G)$. These data suggested that ABPPs not only enhanced the action of NR2A-containing NMDA receptors, but also inhibit the function of NR2B-containing receptors.

\section{Discussion}

In the present study, we originally reported the differential neuroprotective effects of $A$.bidentata polypeptides (ABPPs) on NMDA-induced excitotoxicity in immature and mature cultures, in combined with NR2 subunit specific antagonist. With electrophysiological recording technique, modulation of ABPPs on NMDA receptors was also observed differentially in immature and mature cultured neurons. 
A

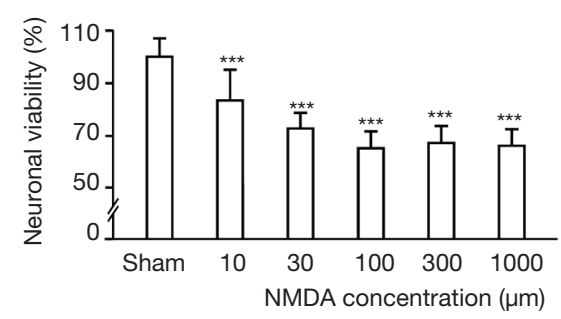

C

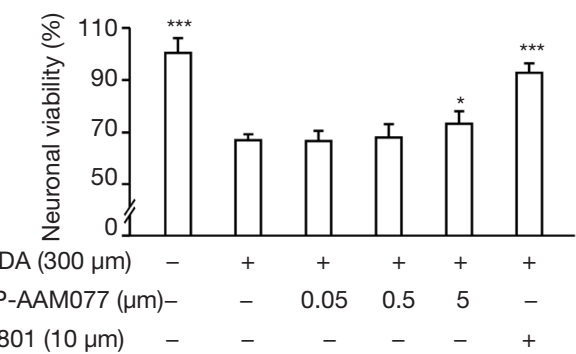

E

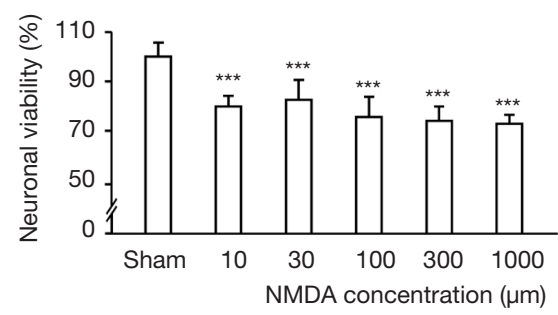

G

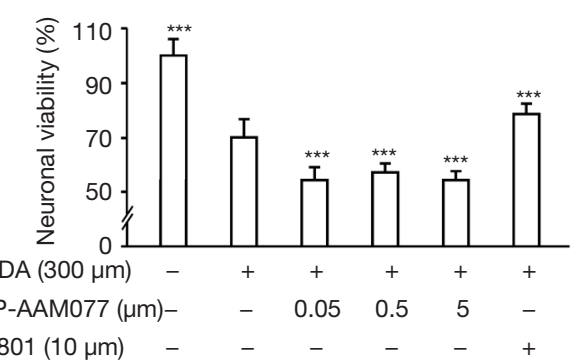

B

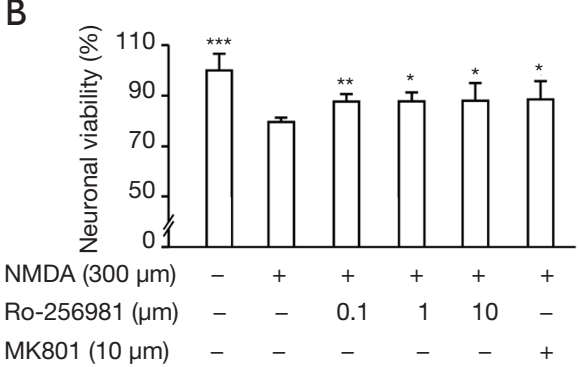

D

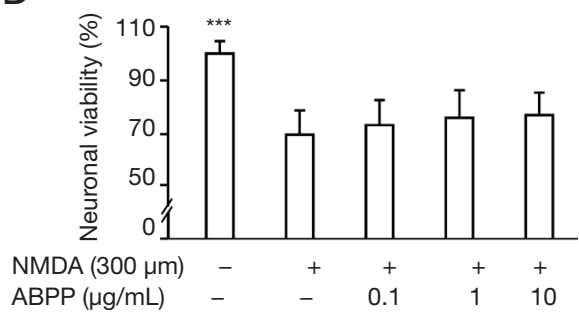

F

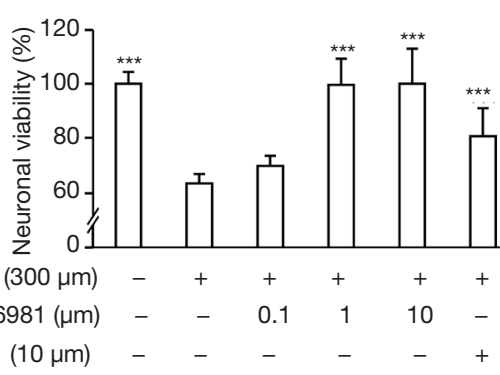

H

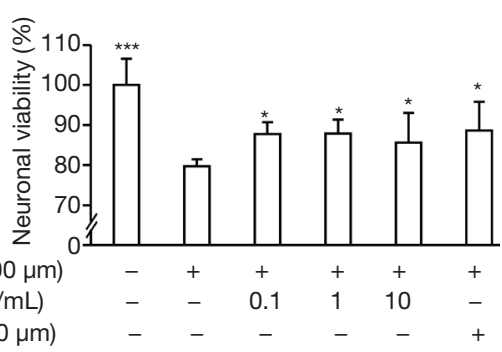

Figure 2 Level of NMDA-induced excitotoxicity was alleviated by ABPP in cultured hippocampal neurons at DIV 14. Cell viability was measured after NMDA stimulation (A-D). A concentration-dependent decrease was induced by NMDA in cell viability of cultured hippocampal neurons (A). Application of Ro-256981 and NVP-AAM077 prevented NMDA-mediated acute excitotoxicity in a concentration-dependent manner (B,C), while application of ABPP $(0.1,1,10 \mu \mathrm{g} / \mathrm{mL})$ could not block NMDA-mediated acute excitotoxicity (D). Cell viability was analyzed at 24 hours after NMDA stimulation (E-H). NMDA induced a concentration-dependent decrease in cell viability of cultured hippocampal neurons (E). Application of Ro-256981 and NVP-AAM077 blocked NMDA-mediated excitotoxicity in a concentration-dependent manner $(\mathrm{F}, \mathrm{G})$, and application of $\mathrm{ABPP}(0.1,1,10 \mu \mathrm{g} / \mathrm{mL})$ prevented NMDA-mediated excitotoxicity $(\mathrm{H})$. NMDA-mediated excitotoxicity also was blocked by $10 \mu \mathrm{M} M \mathrm{MK}-801$ (B, C, F, and $\mathrm{G}) .{ }^{*} \mathrm{P}<0.05,{ }^{* *} \mathrm{P}<0.01,{ }^{* * *} \mathrm{P}<0.001$ vs. control group. The NMDA stimulation neurons were referred as control group (A-H). NMDA, N-methyl-D-aspartate; ABPP, achyranthes bidentata polypeptide. 
A

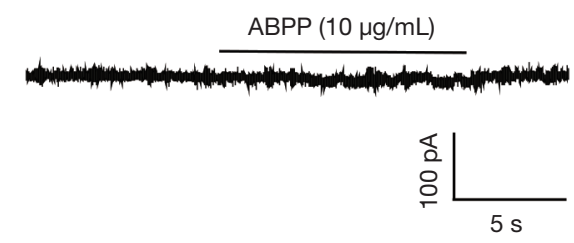

C

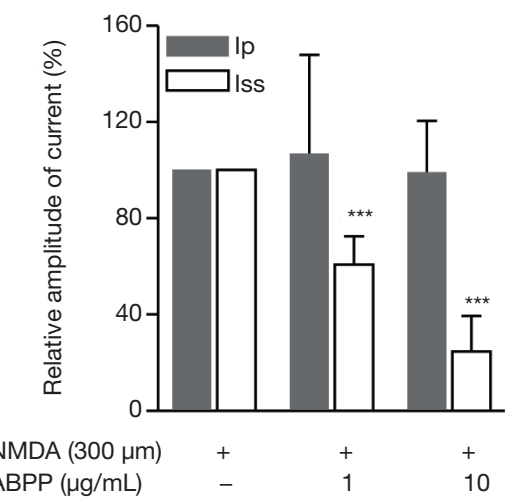

$\mathrm{F}$

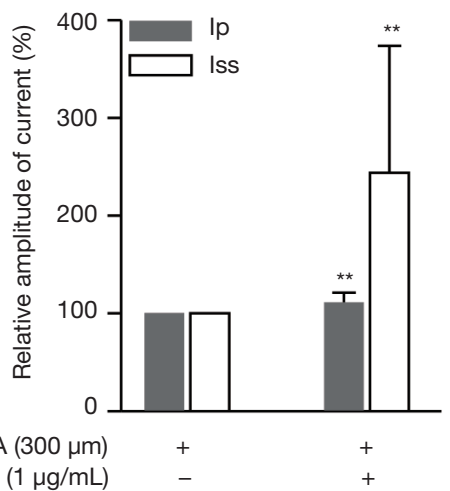

B

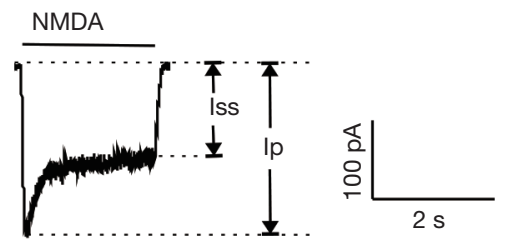

Coefficient of desensitization $=$ Ip-Iss $/ \mathrm{Ip} \times 100 \%$

D

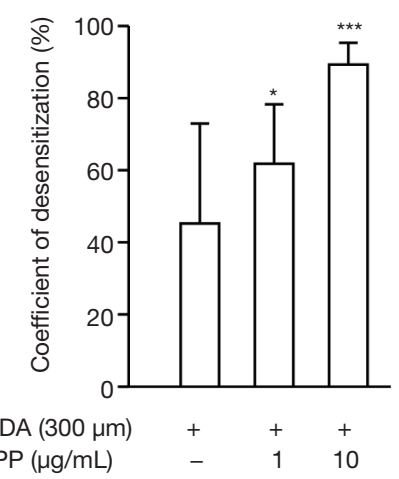

$\mathrm{H}$

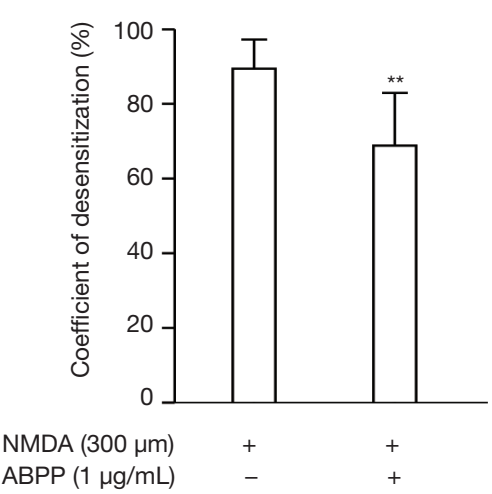

$\mathrm{E}$

$\operatorname{NMDA}(300 \mu \mathrm{m})$

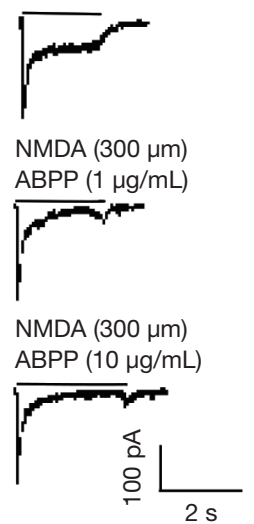

G

$\operatorname{NMDA}(300 \mu \mathrm{m})$

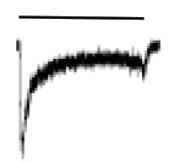

NMDA $(300 \mu \mathrm{m})$ $\operatorname{ABPP}(1 \mu \mathrm{g} / \mathrm{mL})$

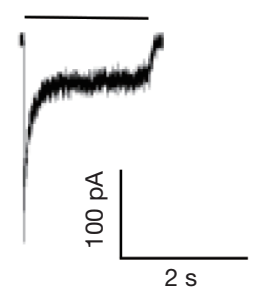

Figure 3 ABPP modulated NMDA-evoked current differentially in cultured hippocampal neurons at DIV 7 and DIV 14. (A,B) The representative traces after addition of ABPP $(10 \mu \mathrm{g} / \mathrm{mL})(A)$, or NMDA $(300 \mu \mathrm{M})(B)$ in the cultured hippocampal neurons. (C) Mean \pm SD of the peak and the sustained state amplitudes of NMDA current in cultured hippocampal neurons at DIV 7 with NMDA (300 $\mu M)$ or application of ABPP $(1,10 \mu \mathrm{g} / \mathrm{mL})$ with NMDA $(300 \mu \mathrm{M})$. (D) Mean \pm SD of coefficient of desensitization of NMDA current. (E) The representative traces of current were evoked by NMDA $(300 \mu \mathrm{M})$ and by NMDA $(300 \mu \mathrm{M})$ with ABPP $(1,10 \mu \mathrm{g} / \mathrm{mL})$ concurrent application in the same cultured hippocampal neuron at DIV 7. (F) Mean \pm SD of the peak and the sustained state amplitudes of NMDA current in cultured hippocampal neurons at DIV 13-14 with NMDA $(300 \mu \mathrm{M})$ alone and ABPP $(1.0 \mu \mathrm{g} / \mathrm{mL})$ with NMDA $(300 \mu M)$. (G) Mean \pm SD of coefficient of desensitization of the NMDA current in. $(\mathrm{H})$ The representative traces of current evoked by NMDA $(300 \mu M)$ and by NMDA $(300 \mu \mathrm{M})$ with ABPP $(1.0 \mu \mathrm{g} / \mathrm{mL})$ in the same cultured hippocampal neuron at DIV $14 .{ }^{*} \mathrm{P}<0.05,{ }^{* *} \mathrm{P}<0.01,{ }^{* * *} \mathrm{P}<0.001 v s$. NMDA $(300 \mu M)-$ evoked current. NMDA, N-methyl-D-aspartate; ABPP, achyranthes bidentata polypeptide. 
Furthermore, in conjunction with NR2 subunit specific antagonist, we confirmed that the differential role of ABPPs on NR2A- and NR2B-containing NMDA receptors.

ABPPs are a composition from the decoction of $A$. bidentata Blume roots, and they are analyzed by HPLC with UV spectrophotometry at different wavelengths (14). Application of ABPPs in vivo has the potential to be a pharmacotherapy intervention for ischemic stroke and Parkinson's disease (25-28). In the serum of patients with Parkinson's disease, glutamate concentration was higher compared to that of healthy subjects (29). Blood glutamate grabbers have proved to be the protective efficacy in the treatment of patients with ischemic stroke (30). These findings suggested that glutamate excitotoxicity plays a critical role in Parkinson's disease and ischemic stroke.

NMDA receptors are a subtype of ionic glutamate receptors, and are characterized of high permeability to calcium ions (18). Considerable literature has demonstrated that calcium influx via NMDA receptor is the key step in glutamate-induced excitotoxicity. In primary hippocampal neurons, NMDA receptors are mainly NR2A- and NR2Bcontaining NMDA receptors, which are blocked by NVPAAM077 and Ro-256981 respectively. Our data confirmed that NR2A- and NR2B-containing receptors contribute to NMDA-evoked current by electrophysiological recording trace in cultured hippocampal neuron (Figure $4 A$ ). Furthermore, NMDA-evoked decrease of cell viability, which was measured immediately after NMDA stimulation, was inhibited by Ro-256981 or NVP-AAM077 in a concentration dependent manner (Figures $1 B, C, 2 B, C$ ). However, treatment of cultures with ABPPs did not reverse the immediate drop of cell viability by NMDA stimulation (Figures 1D,2D). There are two possible explanations for the results. One is that ABPPs have no effects on NMDA receptors; the other is that $\mathrm{ABPPs}$ confer differentially modulation of NR2A- and NR2B- containing NMDA receptors.

Previous studies showed that NMDA-induced neurotoxicity was closely related to the expression and distribution of NR2 subunits, which are changed with development in primary cultured hippocampal neurons $(18,22,24,31)$. Overstimulation of NMDA receptors resulted in the decrease of cellular viability, which was detected at 24-hour after NMDA stimulation, in a concentration dependent manner (Figures 1E,2E). Treatment of neurons with Ro-256981, a specific NR2B subunits antagonist, cut down the decrease of cellular viability by NMDA stimulation in a dose dependent way
(Figures 1F,2F). However, NVP-AAM077, a specific NR2A subunits antagonist, showed different effects in immature hippocampal neurons (DIV 7) and mature hippocampal neurons (DIV 14) (Figures $1 G, 2 G$ ). NVP-AAM077 alleviated cell injury by NMDA stimulation in cultured hippocampal neurons (DIV 7), while it deteriorated cell injury in cultured hippocampal neurons (DIV 14) (Figures $1 G, 2 G)$. Interestingly, ABPPs $(10 \mu \mathrm{g} / \mathrm{mL})$ reversed the decrease of cellular viability by NMDA only in cultured hippocampal neurons (DIV 14), but not in neurons (DIV 7) (Figures 1H,2H). However, treatment of neurons (DIV 7) with ABPPs $(10 \mu \mathrm{g} / \mathrm{mL})$ conferred neuroprotective effect only when NVP-AAM077 was present (Figure 1H). Thus, ABPPs could not block the prompt decrease of cell viability caused by NMDA stimulation because of its opposite modulation of NR2A- and NR2B-containing NMDA receptors.

NMDA receptors, which are ligand dependent ion channels, can be detected by patch clamp recording in whole-cell model. To verify the differential modulation of ABPPs on NR2A- and NR2B-containing NMDA receptors, NMDA (300 $\mu \mathrm{M})$-elicited inward current was recorded in hippocampal neurons (DIV 7) and in neurons (DIV 14). As our previous data from calcium imaging, the sustained state amplitude of NMDA current was inhibited by ABPPs in cultured hippocampal neurons (DIV 7) (Figure 3C,D,E). However, NMDA evoked current was enhanced by ABPPs in neurons (DIV 14) (Figure 3F,G). The data provide another evidence to support that ABPPs conferred differential modulation of NR2A- and NR2Bcontaining NMDA receptors since expression of NR2B subunits are replaced by NR2A subunits in neurons (DIV 14).

To clarify the modulation of ABPPs on NR2B- and NR2A- containing NMDA receptors, NMDA-elicited current was recorded in conjunction with two selective inhibitors of NMDA subunits, Ro 25-6981 and NVPAAM077. When NR2B subunits antagonist Ro 256981 was present, the NMDA current was mediated by NR2A-containing NMDA receptors. In this condition, application of ABPPs raised the amplitude of NMDA current (Figure 4B,C,D). In contrast, when NR2A subunits antagonist NVP-AAM077 was present, the NMDA current was mediated by NR2B-containing NMDA receptors. Therefore, addition of ABPPs inhibited the amplitude of NMDA current (Figure 4E,F,G). Taken together, these data collectively demonstrate that ABPPs inhibited the action of NR2B-containing NMDA receptors, while enhancing the function of NR2A-containing NMDA receptors. Such 
A

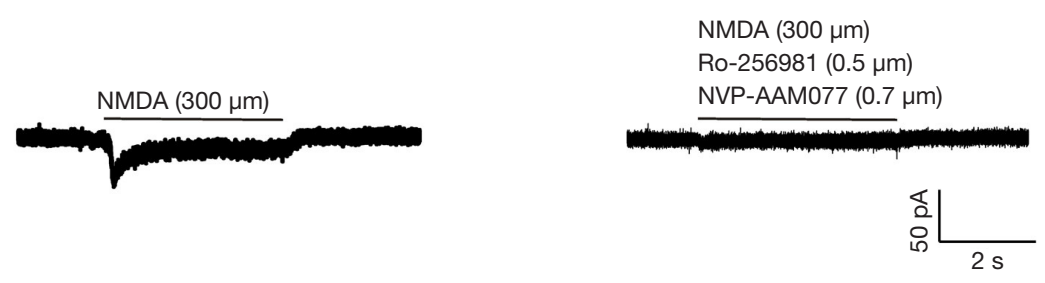

B

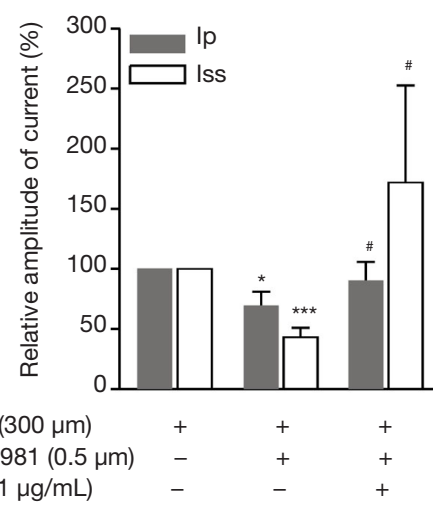

E

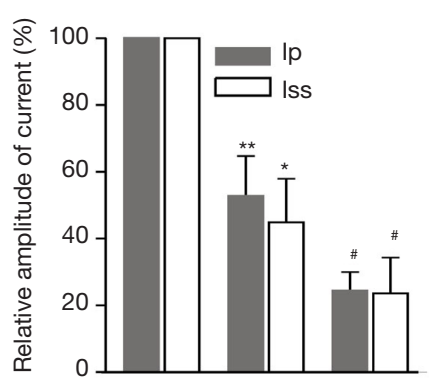
$\begin{array}{llll}\operatorname{NMDA}(300 \mu \mathrm{m}) & + & + & + \\ \operatorname{NVP}-A A M 077(0.7 \mu \mathrm{m}) & - & + & +\end{array}$

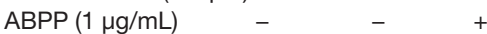

C

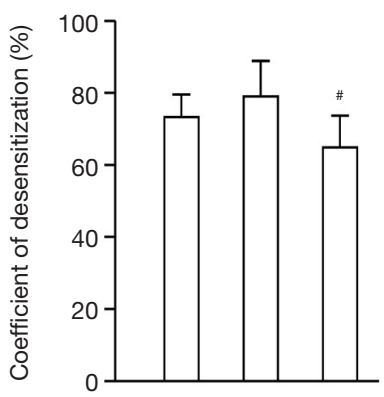

NMDA $(300 \mu \mathrm{m})$ Ro-256981 (0.5 um) - + ABPP $(1 \mu \mathrm{g} / \mathrm{mL})$

$\mathrm{F}$

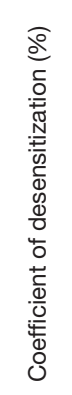

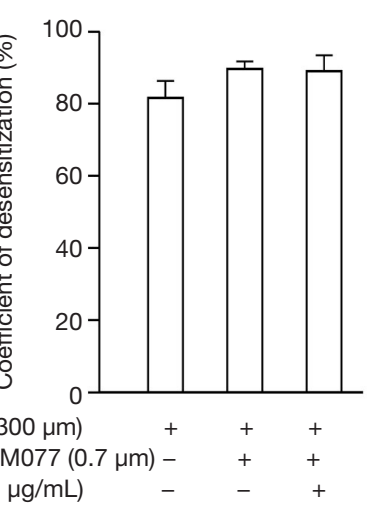

D $\operatorname{NMDA}(300 \mu \mathrm{m})$
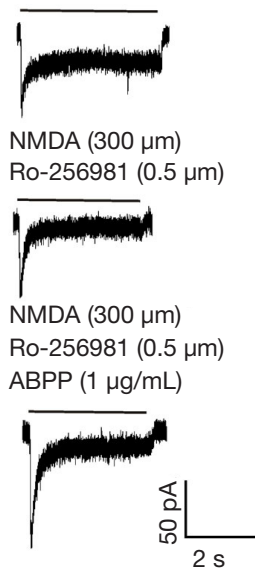

G $\operatorname{NMDA}(300 \mu \mathrm{m})$

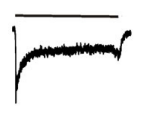

NMDA $(300 \mu \mathrm{m})$ NVP-AAM077 (0.7 $\mu \mathrm{m})$

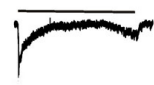

NMDA $(300 \mu \mathrm{m})$ NVP-AAM077 $(0.7 \mu \mathrm{m})$ ABPP $(1 \mu \mathrm{g} / \mathrm{mL})$

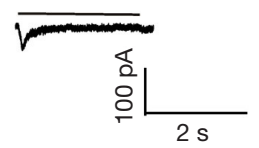

Figure 4 ABPP modulated NR2A- and NR2B-containing NMDA receptors differentially. (A) The representative traces of current evoked by NMDA $(300 \mu \mathrm{M})$ or concurrent application of NMDA $(300 \mu \mathrm{M})$, Ro-256981 $(0.5 \mu \mathrm{M})$ and NVP-AAM077 $(0.7 \mu M)$. (B) Mean \pm SD of the peak and the sustained state amplitudes of NMDA current in cultured hippocampal neurons with NMDA (300 $\mu M$ ), Ro-256981 $(0.5 \mu \mathrm{M})$ with NMDA $(300 \mu \mathrm{M})$, or concurrent application of ABPP $(1.0 \mu \mathrm{g} / \mathrm{mL})$, Ro-256981 (0.5 $\mu \mathrm{M})$ and NMDA (300 $\mu \mathrm{M})$. (C) Mean \pm SD of coefficient of desensitization of the NMDA current. (D) The representative traces of current evoked by NMDA (300 $\mu M$ ), Ro-256981 $(0.5 \mu \mathrm{M})$ with NMDA $(300 \mu \mathrm{M})$, or concurrent application of ABPP $(1.0 \mu \mathrm{g} / \mathrm{mL})$, Ro-256981 (0.5 $\mu \mathrm{M})$ and NMDA (300 $\mu \mathrm{M})$. (E) Mean $\pm \mathrm{SD}$ of the peak and the sustained state amplitudes of NMDA current in cultured hippocampal neurons with NMDA (300 $\mu M)$, NVPAAM077 $(0.7 \mu \mathrm{M})$ with NMDA $(300 \mu \mathrm{M})$, or concurrent application of ABPP $(1.0 \mu \mathrm{g} / \mathrm{mL})$, NVP-AAM077 (0.7 $\mu \mathrm{M})$ and NMDA (300 $\mu \mathrm{M})$. (F) Mean \pm SD of coefficient of desensitization of the NMDA current. (G) The representative traces of current evoked by NMDA (300 $\mu M$ ), NVP-AAM077 $(0.7 \mu \mathrm{M})$ with NMDA $(300 \mu \mathrm{M})$, or concurrent application of ABPP $(1.0 \mu \mathrm{g} / \mathrm{mL})$, NVP-AAM077 (0.7 $\mu$ M) and NMDA $(300 \mu \mathrm{M}) .{ }^{*} \mathrm{P}<0.05,{ }^{* *} \mathrm{P}<0.01,{ }^{* * *} \mathrm{P}<0.001$ vs. NMDA $(300 \mu \mathrm{M})$ evoked current. ${ }^{*} \mathrm{P}<0.05$, vs. Ro-256981 (0.5 $\left.\mu \mathrm{M}\right)$ with NMDA (300 $\left.\mu \mathrm{M}\right)$ evoked current (B,C). ${ }^{\#} \mathrm{P}<0.05$, vs. NVP-AAM077 $(0.7 \mu \mathrm{M})$ with NMDA (300 $\left.\mu \mathrm{M}\right)$ evoked current (E,F). NMDA, N-methyl-D-aspartate; ABPP, achyranthes bidentata polypeptide. 


\section{Page 10 of 11}

differential modulations result in different neuroprotection effects of ABPPs in neurons (DIV 7) and neurons (DIV 14) on NMDA-mediated injury. Further research is needed to identify the key bioactive component of ABPPs, which modulates NR2A- and NR2B-containing NMDA receptors differentially. Moreover, the structure of the component and its molecular interactions with NR2A- and NR2B subunits will be elucidated to shed light on its recombinant by bioengineering and its clinical application in the future.

\section{Acknowledgments}

Funding: The research was supported by National Natural Science Foundation of China (No. 81073079, to Dr. Hongmei Shen); Natural Science Foundation of the Jiangsu High Education Institute of China (No. 18KJA180009, to Dr. Hongmei Shen), and Science Foundation of Nantong City of China (No. MS12018043, to Dr. Hongmei Shen).

\section{Footnote}

Reporting Checklist: The authors have completed the MDAR checklist. Available at http://dx.doi.org/10.21037/atm-20581

Data Sharing Statement: Available at http://dx.doi. org/10.21037/atm-20-581

Conflicts of Interest: All authors have completed the ICMJE uniform disclosure form (available at http://dx.doi. org/10.21037/atm-20-581). HS reports grants from National natural science foundation of china, grants from Natural science foundation of the Jiangsu high education institute of china, grants from Science foundation of Nantong city of china, during the conduct of the study. The other authors have no conflicts of interest to declare.

Ethical Statement: The authors are accountable for all aspects of the work in ensuring that questions related to the accuracy or integrity of any part of the work are appropriately investigated and resolved. The whole study protocol was approved by the Ethics Committee of Nantong University (No. 20080118-001) and all the procedures were followed by the Chinese Guidelines for the Care and Use of Laboratory Animals.

Open Access Statement: This is an Open Access article distributed in accordance with the Creative Commons
Hu et al. Neuroprotection of ABPPs is developmentally regulated

Attribution-NonCommercial-NoDerivs 4.0 International License (CC BY-NC-ND 4.0), which permits the noncommercial replication and distribution of the article with the strict proviso that no changes or edits are made and the original work is properly cited (including links to both the formal publication through the relevant DOI and the license). See: https://creativecommons.org/licenses/by-nc-nd/4.0/.

\section{References}

1. Kessler JP. Control of cleft glutamate concentration and glutamate spill-out by perisynaptic glia: uptake and diffusion barriers. PLoS One 2013;8:e70791.

2. Pal B. Involvement of extrasynaptic glutamate in physiological and pathophysiological changes of neuronal excitability. Cell Mol Life Sci 2018;75:2917-49.

3. van der Zeyden M, Oldenziel WH, Rea K, et al. Microdialysis of GABA and glutamate: analysis, interpretation and comparison with microsensors. Pharmacol Biochem Behav 2008;90:135-47.

4. Dash MB, Douglas CL, Vyazovskiy VV, et al. Longterm homeostasis of extracellular glutamate in the rat cerebral cortex across sleep and waking states. J Neurosci 2009;29:620-9.

5. Oldenziel WH, van der Zeyden M, Dijkstra G, et al. Monitoring extracellular glutamate in hippocampal slices with a microsensor. J Neurosci Methods 2007;160:37-44.

6. Hascup ER, Hascup KN, Stephens M, et al. Rapid microelectrode measurements and the origin and regulation of extracellular glutamate in rat prefrontal cortex. J Neurochem 2010;115:1608-20.

7. Hardingham GE, Bading H. Synaptic versus extrasynaptic NMDA receptor signalling: implications for neurodegenerative disorders. Nat Rev Neurosci 2010;11:682-96.

8. Lynch DR, Guttmann RP. NMDA receptor pharmacology: perspectives from molecular biology. Curr Drug Targets 2001;2:215-31.

9. Laube B, Kuhse J, Betz H. Evidence for a tetrameric structure of recombinant NMDA receptors. J Neurosci 1998;18:2954-61.

10. Waxman EA, Lynch DR. N-methyl-D-aspartate receptor subtype mediated bidirectional control of $\mathrm{p} 38$ mitogenactivated protein kinase. J Biol Chem 2005;280:29322-33.

11. Yoshikawa A, Nishimura F, Inai A, et al. Novel rare variations in genes that regulate developmental change in N-methyl-d-aspartate receptor in patients with schizophrenia. Hum Genome Var 2018;5:17056. 
12. Dumas TC. Developmental regulation of cognitive abilities: modified composition of a molecular switch turns on associative learning. Prog Neurobiol 2005;76:189-211.

13. Davis-Reyes BD, Campbell VM, Land MA, et al. Profile of cortical N-methyl-D-aspartate receptor subunit expression associates with inherent motor impulsivity in rats. Biochem Pharmacol 2019;168:204-13.

14. Shen H, Yuan Y, Ding F, et al. The protective effects of Achyranthes bidentata polypeptides against NMDA-induced cell apoptosis in cultured hippocampal neurons through differential modulation of NR2A- and NR2B-containing NMDA receptors. Brain Res Bull 2008;77:274-81.

15. Tovar KR, Westbrook GL. The incorporation of NMDA receptors with a distinct subunit composition at nascent hippocampal synapses in vitro. J Neurosci 1999;19:4180-8.

16. Zhang SJ, Steijaert MN, Lau D, et al. Decoding NMDA receptor signaling: identification of genomic programs specifying neuronal survival and death. Neuron 2007;53:549-62.

17. Sattler R, Tymianski M. Molecular mechanisms of glutamate receptor-mediated excitotoxic neuronal cell death. Mol Neurobiol 2001;24:107-29.

18. Rambousek L, Kleteckova L, Kubesova A, et al. Rat intrahippocampal NMDA infusion induces cell-specific damage and changes in expression of NMDA and GABAA receptor subunits. Neuropharmacology 2016;105:594-606.

19. Shen H, Pan J, Pan L, et al. TRPC6 inhibited NMDA current in cultured hippocampal neurons. Neuromolecular Med 2013;15:389-95.

20. Curtis MJ, Bond RA, Spina D, et al. Experimental design and analysis and their reporting: new guidance for publication in BJP. Br J Pharmacol 2015;172:3461-71.

21. Sheng M, Cummings J, Roldan LA, et al. Changing subunit composition of heteromeric NMDA receptors during development of rat cortex. Nature 1994;368:144-7.
22. Hardingham G. NMDA receptor C-terminal signaling in development, plasticity, and disease. F1000Res 2019;8:F1000 Faculty Rev-1547.

23. Ikonomidou C, Turski L. Why did NMDA receptor antagonists fail clinical trials for stroke and traumatic brain injury? Lancet Neurol 2002;1:383-6.

24. Hardingham GE, Bading H. The Yin and Yang of NMDA receptor signalling. Trends Neurosci 2003;26:81-9.

25. Shen $\mathrm{H}, \mathrm{Wu} \mathrm{X}, \mathrm{Zhu} \mathrm{Y}$, et al. Intravenous administration of achyranthes bidentata polypeptides supports recovery from experimental ischemic stroke in vivo. PLoS One 2013;8:e57055.

26. Peng S, Wang C, Ma J, et al. Achyranthes bidentata polypeptide protects dopaminergic neurons from apoptosis in Parkinson's disease models both in vitro and in vivo. $\mathrm{Br}$ J Pharmacol 2018;175:631-43.

27. Yu S, Wang C, Cheng Q, et al. An active component of Achyranthes bidentata polypeptides provides neuroprotection through inhibition of mitochondrialdependent apoptotic pathway in cultured neurons and in animal models of cerebral ischemia. PLoS One 2014;9:e109923.

28. Cheng Q, Tong F, Shen Y, et al. Achyranthes bidentata polypeptide $\mathrm{k}$ improves long-term neurological outcomes through reducing downstream microvascular thrombosis in experimental ischemic stroke. Brain Res 2019;1706:166-76.

29. Mironova YS, Zhukova IA, Zhukova NG, et al. [Parkinson's disease and glutamate excitotoxicity]. Zh Nevrol Psikhiatr Im S S Korsakova 2018;118:50-4.

30. da Silva-Candal A, Perez-Diaz A, Santamaria M, et al. Clinical validation of blood/brain glutamate grabbing in acute ischemic stroke. Ann Neurol 2018;84:260-73.

31. Liu Y, Wong TP, Aarts M, et al. NMDA receptor subunits have differential roles in mediating excitotoxic neuronal death both in vitro and in vivo. J Neurosci 2007;27:2846-57.
Cite this article as: $\mathrm{Hu}$ W, He J, Wang Y, Xu L, Zhao Y, Hu X, Shen H. Protective effect of Achyranthes bidentata polypeptides on NMDA-mediated injury is developmentally regulated via modulating NR2A and NR2B differentially. Ann Transl Med 2021;9(3):248. doi: 10.21037/atm-20-581 